University of San Diego

Digital USD

Spring 5-27-2017

\title{
Effects of Hypertension Education and Motivation Interviewing by Staff on Patients' Activation
}

Tammy C. Lu

University of San Diego, tammylu@sandiego.edu

Kathy S. James

University of San Diego, kjames@sandiego.edu

Laura Wolfgang

Stanford Health Care, Iwolfgang@stanfordhealthcare.org

Follow this and additional works at: https://digital.sandiego.edu/dnp

Part of the Behavioral Disciplines and Activities Commons, and the Nursing Commons

\section{Digital USD Citation}

Lu, Tammy C.; James, Kathy S.; and Wolfgang, Laura, "Effects of Hypertension Education and Motivation Interviewing by Staff on Patients' Activation" (2017). Doctor of Nursing Practice Final Manuscripts. 45. https://digital.sandiego.edu/dnp/45

This Doctor of Nursing Practice Final Manuscript is brought to you for free and open access by the Theses and Dissertations at Digital USD. It has been accepted for inclusion in Doctor of Nursing Practice Final Manuscripts by an authorized administrator of Digital USD. For more information, please contact digital@sandiego.edu. 


\section{EFFECTS OF HYPERTENSION EDUCATION AND MOTIVATION INTERVIEWING BY STAFF ON PATIENTS' ACTIVATION}

Authors: Tammy Lu DNP candidate BSN RN; Kathy James DNSc APRN; Laura Wolfgang MSN ANP-BC

Author affiliations: University of San Diego, Hahn School of Nursing and Health Science: Beyster Institute for Nursing Research (Drs. James and Lu); and Qualcomm Health Center, Stanford Health Care (Laura Wolfgang)

Corresponding author: Tammy Lu DNP candidate RN (858) 204-9691 tammycheelu@gmail.com

Funding/support: This study was funded in part by the Stanford University School of Nursing Alumnae Legacy Project 


\begin{abstract}
Objective: This evidence-based practice project piloted a team-based program using Motivational Interviewing (MI) and 5 A's (Assess, Advise, Ask, Assist, and Arrange) to promote healthy behavior and reduce blood pressure at an on-site corporate primary care clinic.

Methods: Patients were counseled using MI and the 5 A's techniques. Patients received an educational booklet, and monthly telephone follow up. Patients returned to clinic 3 months afterwards. Data collected included Dietary Screener Questionnaire scores, blood pressure, and self-rating of concern and motivation.

Results: A total of 4 people participated with variable follow-up. Readiness for change remained stable and confidence scores remained stable or increased. One patient decreased daily amount of fatty, salty and sugary foods, but also of desirable food. In 3 of the 4 patients, blood pressure readings improved or remained the same.
\end{abstract}

Conclusion and Implications: Use of MI may contribute to a patient friendly environment to encourage healthy behavior.

Keywords: health behavior, Motivational Interviewing, blood pressure Word count: 150 


\section{EFFECTS OF HYPERTENSION EDUCATION AND MOTIVATION INTERVIEWING BY STAFF ON PATIENT'S ACTIVATION}

The Joint National Committee defines hypertension as a systolic blood pressure (SBP) equal or greater than $140 \mathrm{mmHg}$ or a diastolic blood pressure (DBP) equal to or greater than 90mmHg. ${ }^{1}$ Hypertension is associated with several health consequences such as cardiovascular disease, renal disease, and cerebrovascular accidents. ${ }^{2}$ The prevalence of hypertension in the US in 2014 was $30.8 \%$ and not at national goals. ${ }^{3}$ From a public health perspective, greater adoption of healthier lifestyles is imperative to reduce hypertension and its related consequences.

The reduction of hypertension may also realize great societal cost savings. Hypertension decreases individual productivity, with 44 hours lost per year to absenteeism ${ }^{5}$ and 156 hours lost per year to presenteeism. ${ }^{6}$ Every $10 \mathrm{mmHg}$ reduction in SBP or $5 \mathrm{mmHg}$ in DBP may reduce the incidence of coronary artery disease by $27 \%$, stroke by $36 \%$, and all-cause mortality by $14 \%{ }^{7}$ Annual personal health care expenditures total more than $\$ 2.5$ trillion and are still increasing. Addressing hypertension may result in cost avoidance by reducing morbidity and mortality, and improving productivity. $\mathrm{NCHS}^{1}$ The population of young adults who may benefit from primary prevention of cardiovascular events and other systemic disease is of great interest for corporate health environments.

The company of concern, located in Southern California, designates on-site clinics for its employees. In addition to primary care management, psychiatry, physical therapy, dietician consultation, acupuncture, and optometry services are available on-site. Some employees choose the on-site clinics as their primary care provider while other employees episodically utilize the on-site clinic. In this diverse patient population, the median age is 35 years and the gender distribution is $75 \%$ male and $25 \%$ female. The majority of these office employees are sedentary 
for most of the day. This company employs many people of South Asian descent, who have higher prevalence of metabolic syndrome. ${ }^{8}$ Those factors in combination can predispose these particular employees to developing hypertension. In one blood pressure screening event of 598 employees, 25\% $(n=149)$ met the criteria for hypertension. There is an opportunity to intervene in patients with elevated blood pressure readings, with or without a diagnosis of hypertension.

\section{Evidence for the Problem}

A literature review assessed the evidence for programs by primary care staff for encouraging healthy behavioral change and reducing blood pressure. Databases accessed included CINAHL, Cochrane Library of Systematic Reviews, Health and Psychosocial Instruments, and Pub Med. Search terms used include: "motivational interviewing," "hypertension," "blood pressure," "medical assistant," "productivity," "unlicensed health personnel," "five A's OR 5 A's," and "DASH diet." The search terms were used in several combinations, either in the title search field or keyword search field. The author's searches yielded a total of 249 articles. The abstracts were scanned for relevancy and 25 studies were reviewed. In the final literature review included 15 studies, comprised of 6 systematic reviews and/or meta-analyses, 4 randomized control trials, 3 case-control studies, and 2 qualitative studies. Studies were ranked according to the hierarchy of evidence as presented by Melnyk and Fineout-Overholt. $^{10}$

The U.S. Preventive Services Task Force endorsed the 5 A's construct of "assess, advise, ask, assist, and arrange" to incorporate behavior counseling interventions into daily practice by using a broad healthcare team. ${ }^{11}$ Use of the 5 A's construct has been successfully demonstrated in implementation projects such as smoking cessation initiatives. ${ }^{11}$ Even though 5 A's has been recommended more than ten years ago, the steps have not been consistently implemented for 
programs like hypertension. In a review of the use of 5 A's for weight loss discussion, many physicians frequently "ask" or "assess" a behavior but not "assist or arrange." 12 The gap in assisting patients and arranging resources to help patients with behavioral change lends itself well to promotion of Motivational Interviewing (MI) and use of a healthcare team within a corporate health environment.

Rollnick and colleagues developed MI as a method of counseling to help patients change behavior towards a number of health issues. ${ }^{9}$ When patients are self-motivated to change, rather than being directed to take action by another person, they are more likely to sustain the behavior change. ${ }^{9}$ Educational interventions alone did not create lasting changes in behavior in terms of blood pressure outcomes. ${ }^{11}$ Therefore, MI is proposed as an intervention to promote behavioral change. MI has not been associated with adverse effects ${ }^{13}$ and has been associated with measurable adherence to healthy behavior change such as diet and exercise. ${ }^{14} \mathrm{MI}$ has been associated with decreases in SBP by $4 \mathrm{mmHg}$ and DBP by $3 \mathrm{mmHg}$ as compared to usual care in randomized control trials. ${ }^{14,15} \mathrm{MI}$ has also been associated with long term changes over greater than one year. ${ }^{16}$ Interviews of patients demonstrated that staff trained in MI were more engaged in encounters, and patients felt guided and motivated rather than directed. ${ }^{17}$

Use of a diary was not tested as a sole intervention, however in conjunction with other interventions like $\mathrm{MI}^{14}$ or structured patient follow-up ${ }^{18,19}$ diary use was associated with improvement in SBP and DBP. In the MI studies, there was heterogeneous use of dietary recommendations. The Heart, Lung, and Blood Institute promoted the Dietary Approaches to Stop Hypertension (DASH) diet, which was associated with an average decrease of 5-6 $\mathrm{mmHg}$ in SBP and $3 \mathrm{mmHg}$ in DBP. ${ }^{1,23}$ 
Some suggest that the type of health professional delivering MI mattered, with physiciandelivery associated with better outcomes compared to nurse-delivery. ${ }^{13}$ However, studies using registered nurses have also demonstrated decreased blood pressure in patients ${ }^{14,15,19}$ Other studies using medical assistants (MA) or layperson health coaches have shown promise. While the use of MA-driven protocols have not been associated with improvements in blood pressure, improvements in other health outcomes such as reduced hemoglobin $\mathrm{A} 1 \mathrm{C}$ to $8.0 \%$ or normal low-density lipoprotein levels have been shown. ${ }^{20}$ Use of health coaching, in which unlicensed laypersons provided counseling, has demonstrated changes in health behavior related to overweight and obesity. ${ }^{21}$ Implementation of MA-driven protocols has been shown to increase process measures such as completed referrals. ${ }^{22}$

Several studies suggest programs conducted in work settings afforded opportune timing for interventions. In an employer-based health environment, monthly follow-up by physicians or nurses was associated with better blood pressure control ${ }^{18,24}$ and greater weight $\operatorname{loss}^{24}$ at 6 months compared to usual care. Employer-based programs to target hypertension projected costs savings related to fewer work days lost to absenteeism ${ }^{19,24}$ and presenteeism. $^{24}$

\section{METHODS}

\section{Framework}

The framework used to guide this EBP project was the Stanford Health Care EvidenceBased Practice Model. This framework was developed by the Stanford Shared Leadership Research and Innovation Council ${ }^{25}$ as a way to incorporate EBP into daily practice. There are five steps in the model: 1) to question actions, 2) systematically investigate, 3) measure an outcome, 4) make a decision regarding practice, and 5) disseminate. ${ }^{25}$ This framework was 
chosen because it is linear, clear, and appropriate to use for evidence based practice projects and quality improvement projects.

\section{Participants and Recruitment}

A standardized patient encounter flowchart used by the MA and nurse practitioner (NP) was developed by the NP and Doctor of Nursing Practice (DNP) student (Figure 1). This protocol was piloted for 5 weeks to enroll patients into the project. During all patient encounters the MA obtained vital signs. If the SBP was greater than $140 \mathrm{mmHg}$ or DBP greater than 90 $\mathrm{mmHg}$ a second reading was obtained at least five minutes later. If the blood pressure reading was still elevated the MA notified the provider. Prior to the end of the encounter patients were approached for recruitment for the project. Due to low patient participation the enrollment period was extended for a total of 9 weeks, which unfortunately did not increase the participation pool.

\section{Project Design}

Prior to implementation, the DNP student collected baseline data for comparative analysis. Patient encounters from 2 months of the previous year were audited. In patients with elevated blood pressure readings the audit identified whether or not blood pressure was addressed in that visit. The DNP student prepared personal educational booklets for patient use, comprised of pre-developed materials such as patient self-assessment of motivation, ${ }^{26,27}$ identification of goals, ${ }^{26,27}$ DASH diet, ${ }^{23}$ and employer-based resources. The DNP student prepared a schematic containing MI style phrases and questions to be used by the project team during follow up (Figure 2). This schematic was based on the MI workshop attended by the project team. $^{27}$

In preparation for the project commencement the team attended a 14-hour MI workshop ${ }^{27}$ by a trainer affiliated with the Motivational Interviewing Network of Trainers. In this workshop 
the team demonstrated techniques in a simulated encounter as a final evaluation of learning. ${ }^{27}$ Consideration of a validated tool used by the patients to evaluate the staff, such as the Client Evaluation of Motivational Interviewing scale, was given. ${ }^{28}$ Given the low historical response rate for psychological surveys of $50 \%{ }^{29}$ and plan for patients to complete another survey, the decision was made against evaluating the patients' perception of the MI communication style.

Once patients with elevated blood pressure were identified and provided verbal assent for participation in the project, the NP completed the patient visit. Using the 5 A's framework the NP assessed for blood pressure concerns and advised the patient on the importance for blood pressure management. The patient's concern about health behaviors and motivation for change was measured using a 10-point Likert scale. Further conversation was elicited using MI technique. ${ }^{9.27}$ The MA afterwards administered the Dietary Screener Questionnaire (DSQ). ${ }^{30}$ If, as defined by the protocol, a patient was motivated and ready for behavioral change, the MA provided health coaching. According to a standardized script, the MA discussed normal blood pressure readings, non-pharmacological methods of lowering blood pressure, and health resources with the patient. The patient received an educational booklet which included a list of employer-sponsored resources, such as on-site dietician consultation, meditation classes, and gym programs. The booklet could be personalized to document motivations, goals, and blood pressure readings. Since the patient was developing his own personal motivations and goals, the MA was not involved in counseling or providing medical advice. In providing the booklet the MA completed the rest of the 5 A's framework by assisting the patient with choosing resources and arranging follow-up. ${ }^{12}$ After the encounter the MA documented the health coaching interaction and noted whether resources were provided to the patient. 
The MA reassessed home blood pressure readings, self-rated levels of concern and motivation, and reinforced MI using monthly telephone or electronic follow-up. After three months patients returned to the clinic, where blood pressure, self-rating of concern and motivation for behavior change ${ }^{9,27}$ were measured and repeat $\mathrm{DSQ}^{30}$ was administered.

\section{Institutional Review Board}

The project was reviewed by the Institutional Review Boards of the University of San Diego and Stanford University. Both boards granted exemption because the project did not meet the federal definition of research or clinical investigation. A written consent form was not used because the interventions used in this EBP project have been studied to be safe. The NP or MA explained expectations for participation in this project and patients provided verbal assent.

\section{Data Analysis Procedure}

During the enrollment period of the project the DNP student generated bi-weekly reports of the number of patients seen by the project team, number of patients with elevated blood pressure, and number of patients who were given health coaching. The report analyzed adherence to the standardized patient encounter flowchart and were shared with the project team.

The DSQ was used to evaluate the patients' behavior change as it pertains to diet. ${ }^{30}$ The DSQ contained 26 items measuring the frequency of consumption of fruits, vegetables, whole grains, red meat, dairy, added sugars and processed meat in the past month. While not all of the items DSQ were validated, ${ }^{31}$ the survey was used as part of the US National Health and Nutrition Examination Survey $2009-2010 .^{30}$ The fruit and vegetable intake items had validity scores ranging from 0.34 to $0.83 .{ }^{32}$ Food frequency scores in the DSQ were measured ordinally, such as every day or once a month. Scores from each item in the DSQ were converted to a daily frequency equivalent. ${ }^{30}$ Items from the daily frequency scores were then grouped into three 
categories: dietary habits high in fat and salt, high in sugar, and desirable habits. Patients rated their level of concern and motivation for changing health behaviors using 10 point Likert scale. ${ }^{9,27}$ Measures of concern and motivation have been frequently used in MI techqniue. ${ }^{9,27}$

If MI and 5 A's approach was effective it was expected that dietary habits would improve by the 3 month follow-up visit. Improvement of dietary habits was defined as decrease in salty food by 1 serving, decrease in fatty and sugary food by 1 serving, and increase in fruits, vegetables or whole grain foods by 1 serving. The blood pressure goals included SBP less than $140 \mathrm{mmHg}$ and DBP less than $90 \mathrm{mmHg}$. It was anticipated that blood pressure decreased at the 3 month follow up, defined as a $25 \%$ reduction in the number of patients with SBP > 140 and DBP > 90 who return three months after the initial health coaching encounter.

\section{RESULTS}

Four patients participated in the program, with ages ranging 30 to 65 . Their ethnicities included Caucasian, Asian, and Hispanic. Successful follow up varied among the participants, therefore data analysis was limited. As seen in Table 1, patients' readiness for behavioral change remained stable over the length of the program. Many patients already reported maximum readiness scores from the beginning of the program, which persisted throughout the program. Confidence scores remained stable or increased for all patients. Of note, Patient C's confidence steadily increased over time.

Table 1. Trend of Self-reported Readiness and Confidence Scores over 4 Months

\begin{tabular}{|c|c|c|c|c|c|c|c|c|}
\hline \multirow[b]{3}{*}{ Patient } & \multicolumn{4}{|c|}{ Readiness } & \multicolumn{4}{|c|}{ Confidence } \\
\hline & \multicolumn{4}{|c|}{ Month } & \multicolumn{4}{|c|}{ Month } \\
\hline & 1 & 2 & 3 & 4 & 1 & 2 & 3 & 4 \\
\hline A & 10 & 10 & - & - & 9 & 10 & - & - \\
\hline B & 10 & - & 10 & - & 10 & - & 10 & - \\
\hline C & 10 & 10 & 10 & 10 & 5 & 7 & 7 & 8 \\
\hline D & 8 & 8 & - & - & 8 & 8 & - & - \\
\hline
\end{tabular}


Dietary behaviors were more difficult to analyze due to low volume of patient follow up. The dietary behaviors among patients varied (Table 2). For example, Patient B consumed 6.726 sugary items daily but Patient D consumed 0.259. Some patients, like Patient A, consumed almost the suggested servings of fruits and vegetables at baseline. ${ }^{23,33}$ Patient $\mathrm{C}$ was the only patient with pre and post comparison data. Patient $\mathrm{C}$ decreased daily fat and salt promoting foods by 1.33 and decreased daily sugar intake by 1.33 items. In contradiction, Patient C also decreased daily intake of desired foods by 1.5 items.

Table 2. Comparison of Dietary Behaviors Before-and-After Intervention

\begin{tabular}{|c|c|c|c|c|c|c|c|c|}
\hline \multirow{2}{*}{$\begin{array}{l}\text { Dietary } \\
\text { Habits }\end{array}$} & \multicolumn{2}{|c|}{ Patient A } & \multicolumn{2}{|c|}{ Patient B } & \multicolumn{2}{|c|}{ Patient C } & \multicolumn{2}{|c|}{ Patient D } \\
\hline & Initial & Final & Initial & Final & Initial & Final & Initial & Final \\
\hline $\begin{array}{l}\text { Fat and salt } \\
\text { promoting }^{\text {a }}\end{array}$ & 0.678 & - & 0.632 & - & 3.474 & 2.144 & 1.474 & - \\
\hline $\begin{array}{l}\text { Sugar } \\
\text { intake }^{b}\end{array}$ & 1.929 & - & 6.726 & - & 1.858 & 0.528 & 0.259 & - \\
\hline $\begin{array}{l}\text { Desired } \\
\text { habits }^{c}\end{array}$ & 4.572 & - & 1.87 & - & 3.798 & 2.298 & 3.144 & - \\
\hline
\end{tabular}

aMeasures of fat and salt promoting dietary habits was computed from the daily consumption scores of fried potatoes, cheese, red meat, pizza, popcorn, and processed meat; ${ }^{b}$ measures of sugary dietary habits were computed from the daily consumption scores of added sugar, sweetened drinks, $100 \%$ juice, ice cream, candy and chocolate, soda and pastries; ' measures of desired dietary habits were computed from the daily consumption scores of fruit, vegetable, whole grain bread, milk, salad, brown rice, beans and tomatoes.

In 3 of the 4 patients, blood pressure readings improved or remained the same (Table 3 ). Patient A's blood pressure reading decreased somewhat. Patient B's blood pressure decreased dramatically. Patient C's blood pressure improved in Month 2 and 3, but started to increase in Month 4. Patient D's blood pressure did not improve and was started oral agents to treat hypertension. 
Table 3. Blood Pressure Measurements Over the Length of the Project

\begin{tabular}{|c|c|c|c|c|c|}
\hline $\begin{array}{c}\text { Patient } \\
\text { Identification }\end{array}$ & Month & $\begin{array}{l}\text { Systolic } \\
\text { Blood } \\
\text { Pressure }\end{array}$ & $\begin{array}{c}\text { Diastolic } \\
\text { Blood } \\
\text { Pressure }\end{array}$ & $\begin{array}{c}\text { Systolic } \\
\text { change } \\
\text { from } \\
\text { baseline }\end{array}$ & $\begin{array}{c}\text { Diastolic } \\
\text { change } \\
\text { from } \\
\text { baseline }\end{array}$ \\
\hline \multirow{4}{*}{ A } & 1 & 149 & 77 & - & - \\
\hline & 2 & 130 & 82 & -19 & +5 \\
\hline & 3 & 137 & 73 & -12 & -4 \\
\hline & 4 & 133 & 84 & -16 & +7 \\
\hline \multirow{4}{*}{ B } & 1 & 168 & 88 & - & - \\
\hline & 2 & - & - & - & - \\
\hline & 3 & 126 & 80 & -42 & -8 \\
\hline & 4 & - & - & - & - \\
\hline \multirow{4}{*}{ C } & 1 & 137 & 81 & - & - \\
\hline & 2 & 130 & 80 & -7 & -1 \\
\hline & 3 & 123 & 83 & -14 & +2 \\
\hline & 4 & 137 & 84 & 0 & +3 \\
\hline \multirow{4}{*}{ D } & 1 & 150 & 82 & - & - \\
\hline & 2 & 168 & 80 & +18 & -2 \\
\hline & 3 & - & - & - & - \\
\hline & 4 & 150 & 90 & 0 & +8 \\
\hline
\end{tabular}

\section{DISCUSSION}

\section{Limitations}

There were fewer than expected participants for this project. Data from fall 2015 showed of the patients seen by the nurse practitioner, there was an average of 17 patients per month presenting with elevated blood pressure. In contrast, only 8 patients seen in the original 4 week recruitment period had elevated blood pressure. Since the number of eligible patients for the project was so low, the recruitment period was extended for a total of 9 weeks, yielding 12 patients with elevated blood pressures and 4 who agreed to participate in the study.

Several reasons exist that may have contributed to the small size of participants. In 2016, dramatic health insurance restructuring occurred, such that employees no longer enjoyed a $\$ 0$ copay. Instead, employees paid more than $\$ 100$ per visit, which was reimbursed through a health 
savings account. As a result the clinics experienced a drastic decrease in patient volume in 2016. Data from Fall 2015 showed an average of 15 patients per day seen by the nurse practitioner, compared to 9 patients per day in Fall 2016. Some patients visited the clinic for an acute illness or injury and but had external primary care providers, therefore participation in the project was not appropriate.

In addition, the project did not begin by the desired start date. The project was originally planned to start in September 2016 with the company annual biometric screening program. Patient's blood pressure, cholesterol, waist circumference, and glucose would be measured during biometric screening. The 2015 experience with biometric screening showed a tendency for patients to book appointments with the clinic because of abnormal findings from the biometric screenings. However, the project did not launch until November 2016, resulting in missed opportunity for potential recruitment.

There were challenges in choosing a tool to measure project outcomes. While dietary behavior was measured, patients may have focused on other identified behavioral change, such as increasing exercise or reducing stress. However, other validated survey tools assessing a wider spectrum of patient behavior or health choices were 30 to 60 items long, which affected the completion rate of such tools. For simplicity, the identified health behavior for this project was dietary change. Consideration was given for a dietary screener with superior validity $(r=0.6-0.7$, $\mathrm{p}<.001)$ such as the Block Fruit Vegetable Fiber Screener. ${ }^{34}$ However, the Block Fruit Vegetable Fiber Screener was proprietary. Contract negotiations lasted two months without resolution, and instead a survey from public domain with lesser validity ${ }^{30,31,32}$ and ease of use was used for the project. 


\section{Cost/Benefit Analysis}

The total cost of the program was $\$ 3,360$ (Table 4). The majority of costs stemmed from training and the associated labor costs for the training. The amount of labor costs from performing telephone follow up was not measured. There were considerable cost savings. The company marketing team provided professional editing, high-quality printing, and shipping of the patient brochures without compensation. The DNP student developed the standardized patient protocol and MI schematic; NP input towards developing those tools was also uncompensated. This project was partially funded by Stanford University School of Nursing Alumnae Legacy Project, which facilitated the launch of this project.

Table 4. Itemized Costs for Initiating Project

\begin{tabular}{lc}
\hline \multicolumn{1}{c}{ Item } & $\begin{array}{l}\text { Total price per } \\
\text { item (dollars) }\end{array}$ \\
\hline MI training workshop & 758 \\
\hline $\begin{array}{l}\text { Labor costs for } \\
\text { attending training } \\
\text { Nurse Practitioner }\end{array}$ \\
\hline \multicolumn{2}{c}{ Medical Assistant } \\
\hline Printing supplies & 2400 \\
\hline Total & 182 \\
\hline
\end{tabular}

In summary, there were substantial initial costs to this program without appreciable immediate costs savings. While reduction in morbidity would take several years before costeffectiveness would be appreciable. However, the young median age and predominantly sedentary lifestyle of employees placed many at high risk for developing hypertension. One can argue there is a great opportunity to motivate employees to be engaged in healthy behaviors as primary and secondary prevention of hypertension as well as other conditions such as overweight, obesity, metabolic syndrome, and diabetes. 
In promoting healthy behavior changes and reducing hypertension, this project may theoretically help reduce overall health care expenditures for society and for the company. Hypertension was associated with $\$ 42.8$ billion in direct medical expenses and $\$ 3.6$ billion lost productivity. ${ }^{33}$ Since one out of every six healthcare dollars is spent on cardiovascular disease, ${ }^{33}$ reductions in blood pressure may realize substantial cost savings. Worksite health promotion programs have been shown to reduce costs related to medical care and absenteeism by $25-30 \% .{ }^{35}$ The return on investment for onsite wellness programs have been estimated to be $\$ 3.27$ in medical costs and $\$ 2.73$ in absenteeism saved for every dollar spent. ${ }^{33}$ In addition, adopting a program to promote healthy lifestyle changes as suggested by the Centers for Disease Control and Prevention ${ }^{35}$ and the Agency for Healthcare Research and Quality ${ }^{36}$ would improve the quality of care delivered by the clinic.

\section{IMPLICATIONS FOR RESEARCH AND PRACTICE}

\section{Options}

If there is continued interest at the clinic site, many options exist for sustaining this program. There may be an opportunity for future grant funding from Stanford Legacy Alumnae Grant. Employing the assistance of another DNP student would employ judicious use of resources. Alternatively, the NP and MA team may choose to continue using MI and 5 A's techniques without continuing telephone follow-up, which was the potentially most labor and time-intensive portion of the project.

Several options exist for further development of this project. The current program was piloted using only one team. There is a possibility of expanding the project to all providers of the two onsite clinics. There is also a potential option to create a clinical decision support tool. For 
example, the electronic health record identified patients with elevated blood pressure and reminded the provider and the medical assistant that an intervention was suggested. This trigger may remind the team to use MI and 5 A's techniques. Analyzing other aspects of the projects may be of interest. For example, instead of measuring dietary behavior, another tool might be selected to measure other health behaviors. Assessing the perceived value of MI from the perspective of the patient may be fruitful. Extending the intervention to a full 12-month period may better reveal the effect on blood pressure and behavior changes.

\section{Barriers/Resistance}

Several factors contributed to the delay for the project launch. The project was funded by the Stanford University School of Nursing Alumnae Legacy Project. Extra time was needed for approval of the project due to the complex leadership structure. Healthcare services in the clinic were provided by a contracted entity, therefore local and remote management were involved in the oversight of this project.

Upon expanding on this project in the future, some barriers present at the launch of this project may no longer be an in issue. A team trained in MI now exists, therefore the initial hurdle of funding and training a team has passed. New knowledge that selection of survey tools, particularly a proprietary one, requires more planning than anticipated, can aid in future planning.

In replicating this project in the community, resistance from the front-line staff, including providers, nurses and MA may be expected. Evidence does suggest that use of staff RNs and/or MAs can effectively help patients keep blood pressure under control. ${ }^{15,19,20,24}$ MAs may become resistant to this program due to the added workload. A timed study involving a MA-based program for promoting health behavior found that an average of 5.4 minutes per patient was 
added to the workload. ${ }^{22}$ To overcome this possible resistance, it would be helpful to revisit the job description and opportunities for job growth in a given clinic. In the case of this clinic, health coaching is built into the clinical ladder for an MA, providing opportunities for career advancement. In addition, use of a pilot team as described in this project to evaluate the feasibility at a given clinic would be wise.

\section{Conclusion}

The project involved the use of MI and the 5 A's to promote healthy behavior and reduce hypertension. There is an ongoing need to reduce the prevalence of hypertension in the U.S. due to the association with several comorbidities and health complications. There is a need for an evidence-based program to promote healthy and lasting behavior changes in patients. The use of MI in primary care by providers and other healthcare professionals has been shown to be effective in decreasing blood pressure and sustaining change. The 5 A's construct promoted by the U.S. Preventive Task Force can be an effective, unifying framework to address behavior change regularly and invoke interdisciplinary teamwork.

At this clinic, this project demonstrated that MAs could provide health coaching and follow-up, and were an important part of an interdisciplinary team. Patient participation was low, therefore the effects on workload were uncertain. In corporate health environments, prevention of the complications of hypertension is essential for maintaining a healthy and productive workforce. 


\section{REFERENCES}

1. U.S. Department of Health and Human Services, National Institutes of Health, National Heart, Lung, and Blood Institute, National High Blood Pressure Education Program. Reference card from the Seventh Report of the Joint National Committee on prevention, detection, evaluation, and treatment of high blood pressure. NIH Publication No. 035231. http://www.nhlbi.nih.gov/files/docs/guidelines/phycard.pdf. Published May 2003. Accessed February 17, 2016.

2. American Heart Association. Why blood pressure matters. http://www.heart.org/HEARTORG/Conditions/HighBloodPressure/WhyBloodPressureM atters/Why-Blood-Pressure-Matters_UCM_002051_Article.jsp\#.Vt0EQNCo1QI. Accessed February 8, 2015.

3. U.S. Department of Health and Human Services, Centers for Disease Control and Prevention, National Center for Health Statistics. Health, United States, 2015. DHHS Publication No. 2016-1232. https://www.cdc.gov/nchs/data/hus/hus15.pdf. Published May 2016. Accessed January 15, 2017.

4. U.S. Department of Health and Human Services, Office of Disease Prevention and Health Promotion. 2020 Topics \& Objectives: Heart Disease and Stroke.

http://www.healthypeople.gov/2020/topics-objectives/topic/heart-disease-and-stroke. Last updated February 2, 2017. Accessed February 2, 2017.

5. U.S. Department of Health and Human Services, Centers for Disease Control and Prevention, National Center for Health Statistics. 2006 National Health Interview Survey (NHIS). Hyattsville, MD: National Center for Health Statistics; 2007. Accessed Feb 19, 2016. 
6. Goetzel RZ, Long SR, Ozminkowski RJ, et al. Health, absence, disability, and presenteeism cost estimates of certain physical and mental health conditions affecting U.S. employers. J Occup Environ Med. 2004;46:398-412.

7. Moran AE, Odden MC, Thanataveerat A, et al. Cost-effectiveness of hypertension therapy according to 2014 Guidelines. N Engl J Med. 2015;372:447-55. doi: 10.1056/NEJMsa1406751.

8. Balasubramanyam A, Rao S, Misra R, Sekhar R, Ballantyne C. Prevalence of metabolic syndrome and associated risk factors in Asian Indians. J Immigrant Minority Health. 2008;10:313-323. doi: 10.1007/s10903-007-9092-4.

9. Rollnick S, Miller W, Butler CC. Motivational Interviewing in Health Care. New York, NY: The Guilford Press; 2008.

10. Melnyk BM, Fineout-Overholt E. Evidence-based practice in nursing and healthcare: $a$ guide to best practice. $3^{\text {rd }}$ ed. Philadelphia, PA: Wolters Kluwer \& Lipppincott, Williams \& Wilkins, 2014.

11. Whitlock EP, Orleans CT, Pendor N, Allan J. Behavioral counseling interventions: An evidence-based approach. Am J Prevent Med, 2002;22:267-284.

12. Sherson EA, Jimenez EY, Katalanos N. A review of the use of the 5 A's model for weight loss counselling: Differences between physician practice and patient demand. Fam Pract. 2014;31:389-398. doi:10.1093/fampra/cmu020

13. Rubak S, Sandboek A, Lauritzen T, Christensen B. (2005). Motivational interviewing: A systematic review and meta-analysis. Br J Gen Pract. 2005;55:305-312.

14. Ma C, Zhou Y, Zhou W, Huang C. Evaluation of the effect of motivational interviewing counselling on hypertension care. Patient Educ Couns. 2014;95:231-237. 
15. Dean SC, Kerry SM, Khong TK, Kerry SR, Oakeshott P. Evaluation of a specialist nurseled hypertension clinic with consultant backup in two inner city general practices: Randomized controlled trial. Fam Prac. 2014;31:172-179.

16. Lundahl BW, Kunz C, Brownell C, Tollefson D, Burke BL. A meta-analysis of motivational interviewing: Twenty-five years of empirical studies. Research on Social Work Practice. 2010;20:137-60.

17. Drevenhorn E, Bengtson A, Kjellgren KI. To be motivated or only comply - patient's views of hypertension care after consultation training for nurses. Health Education Journal. 2015;74:28-36.

18. Greene BL, Miller JD, Brown TM, et al. Economic impact of the BP DownShift Program on blood pressure control among commercial driver license employees. J Occup Environ Med. 2009;51: 542-553.

19. Loeppke R, Nicholson S, Taitel M, et al. The impact of an integrated population health enhancement and disease management program on employee health risk, health conditions, and productivity. Popul Health Manag,, 2008;11:287-296.

20. Willard-Grace R, Chen EH, Hessler D, et al. Health coaching by medical assistants to improve control of diabetes, hypertension and hyperlipidemia for low-income patients: A randomized controlled trial. Ann Fam Med, 2015;13:130-138.

21. Adelman AM, Graybill M. Integrating a health coach into primary care: Reflections from the Penn State Ambulatory Research Network. Ann Family Med. 2005;3(Suppl 2):S33S35. doi: 10.1370/afm.317 
22. Ferrer RL, Mody-Bailey P, Jaen CR, Gott S, Araujo S. A medical assistant-based program to promote healthy behaviors in primary care. Ann Family Med. 2009;7:504512. doi: 10.1370/afm.1059

23. U.S. Department of Health and Human Services, National Institutes of Health, National Heart, Lung, and Blood Institute. Lifestyle interventions to reduce cardiovascular risk: Systematic evidence review from the Lifestyle Work Group,2013. https://www.nhlbi.nih.gov/sites/www.nhlbi.nih.gov/files/lifestyle.pdf. Published 2013. Accessed March 2, 2016.

24. Groeneveld IF, Proper KI, van der Beek AJ, van Mechelen W. Sustained body weight reduction by an individual-based lifestyle intervention for workers in the construction industry at risk for cardiovascular disease: Results of a randomized control trial. Prev Med. 2010;51:240-246.

25. Reichert KB, Borja J. Let's Implement: Practice Change and Evidence-based Practice [Powerpoint presentation]. Palo Alto, California: Shared Leadership Research \& Innovation Council, Stanford Health Care; 2015.

26. Glasgow RE, Emont S, Miller DC. Assessing delivery of the five 'As' for patient-centered counseling. Health Promot Int. 2006;21:245-254. doi: 10.1093/heapro/dal017

27. Matulich B. Motivational Interviewing an introductory workshop [Powerpoint presentation]. San Diego, California: Bill Matulich. August 25, 2016.

28. Madson MB, Mohn RS, Schumacher JA, Landry AS. Measuring client experiences of Motivational Interviewing during a lifestyle intervention. Measurement and Evaluation in Counseling and Development, 2015;48:140-151. 
29. Van Horn PS, Green KE, Martinussen M. Survey response rates and survey administration in counseling and clinical psychology: A meta-analysis. Educational and Psychological Measurement, 2008;69:389-403.

30. U.S. Department of Health and Human Services, National Institutes of Health, National Cancer Institute, Epidemiology and Genomics Research Program. Dietary Screener Questionnaires (DSQ) in the NHANES 2009-10: DSQ. https://epi.grants.cancer.gov/nhanes/dietscreen/questionnaires.html. Updated November 18, 2016. Accessed September 25, 2016.

31. Yaroch AL, Tooze J, Thompson FE, et al. Evaluation of three short dietary instruments to assess fruit and vegetable intake: The National Cancer Institute's Food Attitudes and Behaviors (FAB) Survey. J Acad Nutr Diet. 2012;112:1134-1137.

32. George SM, Thompson FE, Midthune D, et al. Strength of the relationships between three self-reported dietary intake instruments and serum carotenoids: the Observing Energy and Protein Nutrition (OPEN) Study. Public Health Nutr. 2012;15:1000-1007.

33. CDC Foundation. Business Pulse: How the CDC protects the health of your business. http://www.cdcfoundation.org/businesspulse/heart-health. Accessed March 3, 2017.

34. NutritionQuest. Dietary Fruit-Vegetable-Fiber Screener. Berkeley, CA: NutritionQuest, 2016.

35. Centers for Disease Control and Prevention, National Center for Chronic Disease Prevention and Health Promotion, Division for Heart Disease and Stroke Prevention. The CDC Worksite Health ScoreCard: An Assessment Tool for Employers to Prevent Heart Disease, Stroke, and Related Health Conditions. Atlanta: U.S. Department of Health and Human Services; 2014. 
36. Agency for Healthcare Research and Quality, United States Preventive Services Task Force. The Guide of Clinical Preventive Services 2014. http://www.uspreventiveservicestaskforce.org/Page/Name/tools-and-resources-for-betterpreventive-care. Accessed January 6, 2015. 


\section{APPENDIX A}

Figure 1. Flowchart depicting process for enrollment and follow-up for the project.

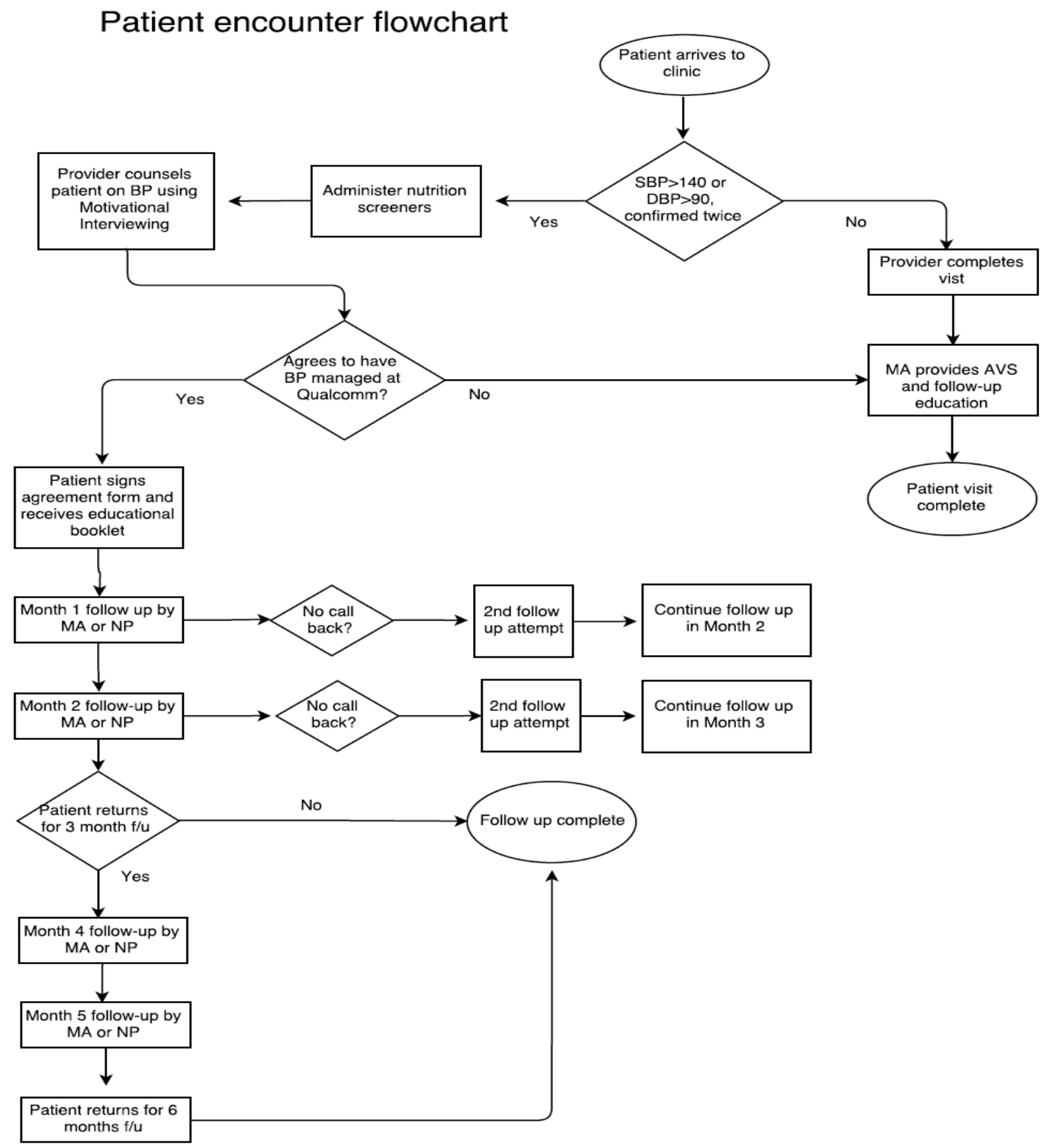


Figure 2. Schematic with scripted questions and responses based on Motivational Interviewing. The schematic was used during the enrollment phase and during follow-up. The interviewer begins using the schematic from the lower left corner with Contemplation and Precontemplation. If the patient was resistant to the conversation, the interviewer would move to the lower right corner and use scripted phrases for Sustain Talk. The ultimate goal is to guide patients through the interview towards the upper left corner towards Change Talk.

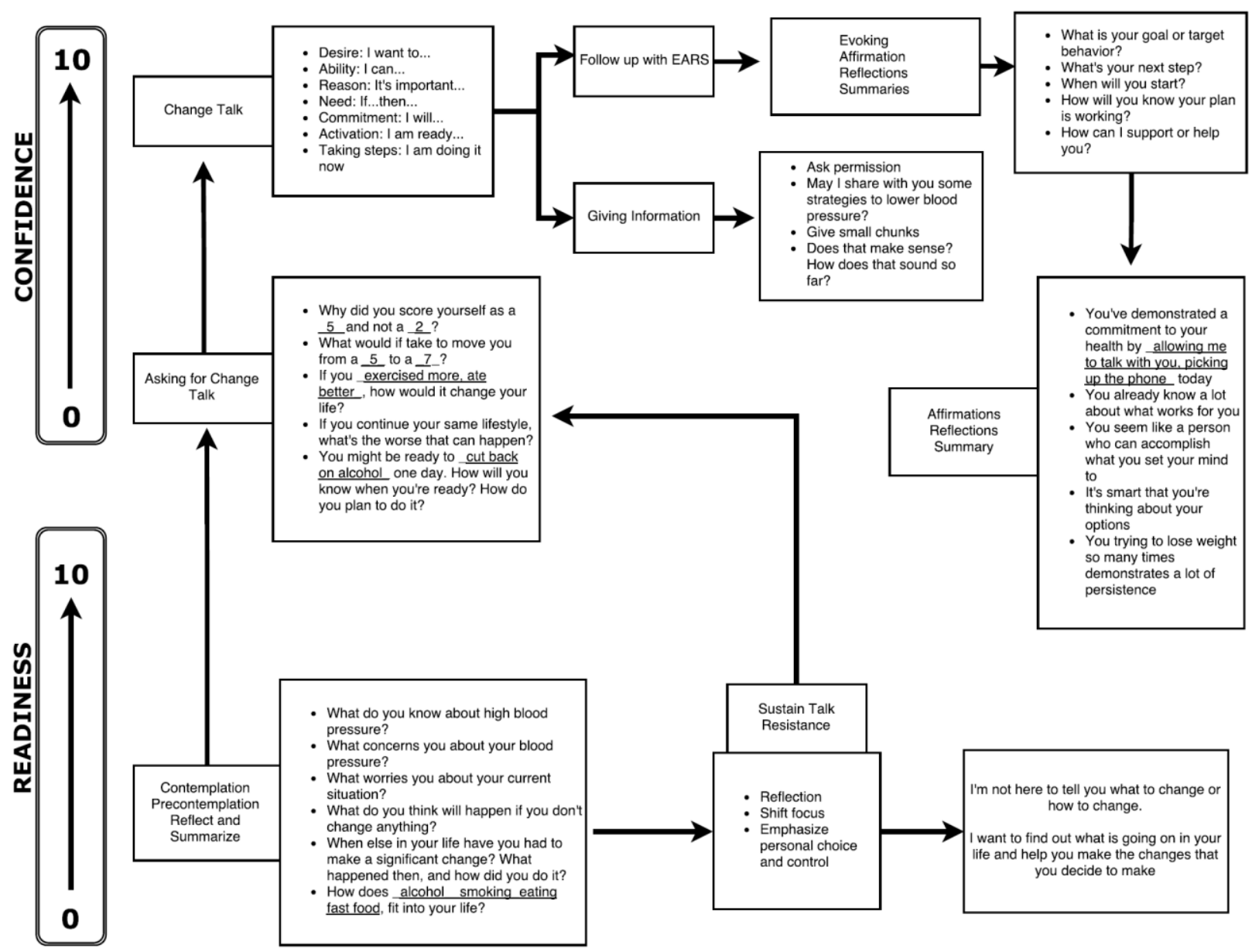




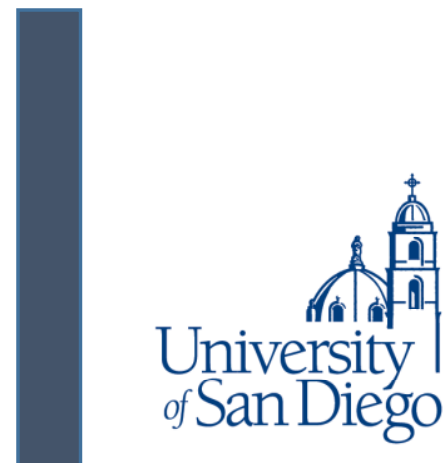

\author{
APPENDIX B \\ IRB EXEMPTION FORMS
}

\title{
Institutional Review Board Project Action Summary
}

Action Date:

July 13, 2016

Note: Approval expires one year after this date.

Type: __New Full Review ___New Expedited Review __ Continuation Review _ X_Exempt Review Modification

Action: X__Approved

__Approved Pending Modification Not Approved

Project Number: $\quad$ 2016-07-256

Researcher(s): $\quad$ Tammy Lu DNP student SON

Dr. Kathy James Fac SON

Project Title: Effects of Hypertension Education and Motivation Interviewing by Staff on Patient's Activation

Note: $\quad$ We send IRB correspondence regarding student research to the faculty advisor, who bears the ultimate responsibility for the conduct of the research. We request that the faculty advisor share this correspondence with the student researcher.

\section{Modifications Required or Reasons for Non-Approval}

None

The next deadline for submitting project proposals to the Provost's Office for full review is N/A. You may submit a project proposal for expedited review at any time.

Dr. Thomas R. Herrinton

Administrator, Institutional Review Board

University of San Diego

herrinton@sandiego.edu

5998 Alcalá Park

San Diego, California 92110-2492 


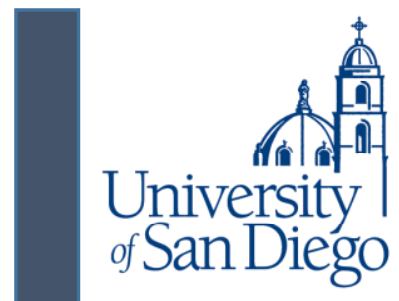

\section{Institutional Review Board Project Action Summary}

Action Date:

December 5, 2016

Type: __New Full Review _ New Expedited Review ___Continuation Review Exempt Review X__Modification

Action: X_Approved Approved Pending Modification Not Approved

Project Number: $\quad$ 2016-07-256

Researcher(s): $\quad$ Tammy Lu DNP student SON Dr. Kathy James Fac SON

Project Title: Effects of Hypertension Education and Motivation Interviewing by Staff on Patient's Activation

Note: $\quad$ We send IRB correspondence regarding student research to the faculty advisor, who bears the ultimate responsibility for the conduct of the research. We request that the faculty advisor share this correspondence with the student researcher.

\section{Modifications Required or Reasons for Non-Approval}

None

The next deadline for submitting project proposals to the Provost's Office for full review is N/A. You may submit a project proposal for expedited review at any time.

Dr. Thomas R. Herrinton

Administrator, Institutional Review Board

University of San Diego

herrinton@sandiego.edu

5998 Alcalá Park

San Diego, California 92110-2492 